\title{
Listeriosis: A Life Threatening Bacterial Zoonosis of Global Importance
}

\author{
Mahendra Pal* \\ Founder Director of Narayan Consultancy on Veterinary Public Health and \\ Microbiology, Gujarat, India \\ *Corresponding Author: Mahendra Pal, Founder Director of Narayan Consultancy \\ on Veterinary Public Health and Microbiology, Gujarat, India.
}

Received: August 26, 2020

Published: October 15, 2020

(C) All rights are reserved by Mahendra Pal.
There are many bacterial zoonotic diseases, such as anthrax, brucellsois, campylobacteriosis, erysipelothricosis, leptospirosis, listeriosis, Lyme disease, meliodosis, salmonellosis, staphylococcosis, streptococcosis, tetanus, tuberculosis, tularaemia, and yersiniosis, which have significant impact on human and animal health [1]. Among these, listeriosis is an infectious, life threatening bacterial zoonosis of global public importance [1]. Disease is reported from many countries of the world including India [1-8]. It occurs in sporadic or epidemic form in humans and animals including birds. During the recent years, the organism has emerged as an important food borne pathogen responsible for many outbreaks in human beings in several countries including Australia, Canada, France, Switzerland, and USA $[1,9,10]$. Murray is credited to describe the disease in 1926 for the first time in rabbit and guinea pig [1]. Later, Nyfeldt in humans and Gill in domestic animals recorded the infection for the first time in 1929 and 1937, respectively. The name Listeria monocytogenes was proposed by Pirie in 1940 in the honour of the Lord Joseph Lister, the surgeon and the pioneer in antisepsis and for its effect on monocytes [11]. In USA, about 1700 cases of sporadic listeriosis with 550 deaths are reported each year [12].

There are eight documented species in the genus Listeria, which includes L. monocytogenes, L. ivanovii, L. innocua, L. welshimeri, L. seeligeri, L. grayi, L. marthii and L. rocourtiae [13]. Among these, L. monocytogenes is mainly implicated in the etiology of human (98\%) and animal (85\%) disease [14]. Listeria monocytogenes is a Gram positive, 0.5 - $2.0 \mu \mathrm{m}$ in length, aerobic or facultative anaerobic, non-capsulated, non-spore forming, motile at $20-25^{\circ} \mathrm{C}$, pleomorphic or rod shaped organism [1]. It can survive in wide range of temperature $\left(-1.5^{\circ} \mathrm{C}\right.$ to $\left.45^{\circ} \mathrm{C}\right)$. Based on antigenic structures, 13 serovars of $L$. monocytogenes have been identified, and about $95 \%$ of human infections are caused by serotypes $1 / 2 \mathrm{a}, 1 / 2 \mathrm{~b}, 1 / 2 \mathrm{c}$, and
$4 \mathrm{~b}$ [8]. The pathogen has been reported in humans, and a wide variety of animals, such as cattle, sheep, goat, horse, pig, buffalo, dog, chinchilla, mink, rabbit, gerbil, mice, ferret, guinea pig, turkey, canary, duck, and fowl [1]. The bacterium is ubiquitous in distribution inhabiting the soil, silage, litter, sewage, decaying vegetable matter, manure, water, animal feed, fresh and frozen poultry, processed meat, raw milk, cheese, sea foods, and in faecal matter of healthy humans and animals $[1,7,15]$. The organism can survive and grow over a wide range of environmental conditions, such as refrigeration temperatures, low $\mathrm{pH}$, and high salt concentration [10].

The principal mode of transmission is by ingestion of contaminated feed/food in animals and human, respectively. However, infection can also be acquired through direct contact with infected material, especially in veterinarians, animal handlers, farmers, and abattoir workers $[16,17]$. Transmission by sexual contact is also described as the organism is excreted in the semen. Neonatal infection in new born children and nosocomial infection in hospital and institution is also reported [1]. The virulence factors like internalin, listeriolysin $\mathrm{O}$ and act $\mathrm{A}$ are mainly involved in the pathogenesis of the disease. T-cell mediated immunity plays a vital role in the host defense [18].

The incubation period of listeriosis in humans is 4 to 21 days [1]. It is mentioned that new born infants and persons above 50 years of age are most susceptible [10]. Clinical spectrum of disease in humans include mild flu-like illness, fever, headache, abdominal pain, diarrhoea, conjunctivitis, pneumonia, urethritis, abortion or still birth or neonatal death, and papular exanthema on the arms besides septicemia, meningitis, encephalitis, and endocarditis [1]. The mortality from listeric meningitis may be as high as 70\%. [10]. In animals, clinical symptoms, such as circling movement, incordination, listenessness, anorexia, fever, marked salivation, drooping 
of ear, dysphagia, paralysis of facial and throat muscles, meningoencephalitis, mastitis, and abortion are observed [1].

Listeriosis is an opportunistic and nosocomial zoonosis of global significance, and often causes fatal disease in those with weak immune system like infants or elderly persons, pregnant women, persons with chronic disease or long term therapy, HIV and cancer patients. A number of food borne outbreaks and sporadic cases have been reported in different parts of world involving consumption of contaminated food mostly of animal origin $[4,10]$. Sporadic and epidemic cases are reported in different species of animals [19]. The occurrence of the pathogen in the different types of food like raw milk, pasteurized milk, sot cheese, ice cream, red meat, poultry meat, egg, fish, sea-foods, fruits, vegetable, and their processing plant have been reported by several investigators [7-9,14]. These foods serves as important sources of L. monocytogenese [10].

The diagnosis of disease can be done by computed tomography/ magnetic resonance imaging (MRI) in case of meningitis, gross and histopathology besides direct microscopy. However, unequivocal diagnosis is established by cultural isolation of the pathogen on selective media like Oxford agar, PALCAM agar, and its identification by performing biochemical tests. In addition, serological methods (compliment fixation, ELISA) and molecular techniques like PCR can be performed on clinical samples of humans and animals as well as on various types of food [1,8]. Listeriosis should be differentiated from tuberculous and cryptococcal meningitis in humans and rabies, brucellosis, toxoplasmosis and bovine spongiform encephalopathy (BSE) in animals [18]. Recently, Pal and co-workers (2016) published a review on current molecular techniques for the diagnosis of listeriosis.

A number of antibacterial antibiotics, such as ampicillin, chloramphenicol, enrofloxacin, kanamycin, perfloxacin and tetracycline have been tried in humans as well as in animals [10]. Ampicillin is the drug of choice for the treatment of maternal foetal listeriosis. It is advised that tetracycline should not be given in children less than 7 year of age [1]. Prevention and control measures include avoiding consumption of contaminated foods, careful handling of the infected material, ingestion of cooked meat, and pasteurized milk, restraining of pregnant women to handle diseased animals, using protective clothing including gloves while removing retained placenta in animals, disinfection of premises where an animal aborted, immunization of sheep, avoiding cross contamination, use of bacteriocins in food and application of HACCP principles in food processing plant [1,5]. Hitherto, no effective vaccine is available to immunize the humans. Therefore, it is highly imperative that correct early diagnosis and prompt treatment along with effective epidemiological investigation can minimize the incidence of listeriosis.

Further studies on the improvement in the surveillance system, molecular typing of the pathogenic strains of L. monocytogenese in various foods, and determining its ecological niche are recommended.

\section{Acknowledgements}

The authors are very thankful to Prof. Dr. R. K. Narayan for his suggestions during the preparation of manuscript and Anubha Priyabandhu for computer help.

\section{Bibliography}

1. Pal M. "Zoonoses". Second edition. Satyam Publishers, Jaipur, India (2007).

2. Bhujwala RA., et al. "Genital listeriosis in Delhi- A pilot study". Indian Journal of Medical Research 61 (1973): 1284-1288.

3. Gogate AA and Deodhar LP. "Meningitis due to Listeria monocytogenes: (a case report)". Journal of Postgraduate Medicine 27 (1981): 240-242.

4. Gellin BG., et al. "The epidemiology of listeriosis in the United States, 1986. Listeriosis Study Group". American Journal of Epidemiology 133 (1991): 39-401.

5. Tappero JW., et al. "Reduction in the incidence of human listeriosis in the United States: effectiveness of prevention efforts?" Journal of the American Medical Association 273 (1995): 11181122.

6. Malik SV., et al. "Listeric infections in humans and animals in the Indian subcontinent: a review". Tropical Animal Health and Production 34 (2002): 359-81.

7. Mulu S and Pal M. "Studies on the prevalence, risk factors, public health implications and antibiogram of Listeria monocytogenes in sheep meat collected from municipal abattoir and meat shops in Addis Ababa". Journal of Foodborne and Zoonotic Diseases 4 (2016): 1-14.

8. Pal M., et al. "Current molecular techniques for the diagnosis of listeriosis". Journal of Natural History 11 (2016): 20-28. 
9. Rocourt J., et al. "Epidemiology of human listeriosis and seafoods". International Journal of Food Microbiology 62 (2000): 197-209.

10. Pal M., et al. "Growing importance of listeriosis as foodborne disease”. Journal of Experimental Chemistry 3 (2017): 1- 4.

11. Gray MJ and Killinger AH. "Listeria monocytogenes and listeric infections”. Bacteriological Reviews 30 (1966): 309-382.

12. Pal M. "Importance of zoonoses in public health". Indian Journal of Animal Sciences 75 (2005): 586-591.

13. Mendonca M., et al. "Highly specific fiber optic immunosensor coupled with immunomagnetic separation for detection of low level of Listeria monocytogenes and L. ivanovii". Biomedical Center Microbiology 12 (2012): 1-15.

14. Pal M and Awe H. "Public health significance of Listeria monocytogenese in milk and milk products". Journal of Veterinary Public Health 12 (2014): 1-5.

15. Aghi HM., et al. "Occurrence of Listeria in animal feacal matter, farmyard manure and sewage". Indian Journal of Animal Sciences 74 (2004): 737-738.

16. Mclauchlin J and Low JC. "Primary cutaneous listeriosis in adults: an occupational disease of veterinarians and farmers". Veterinary Record 31 (1994): 615-617.

17. Pal M., et al. "Zoonoses occupationally acquired by abattoir workers". Journal of Environmental and Occupational Science 2 (2013): 155-162.

18. Pal M. "Emerging and re-emerging bacterial pathogens of public health concern. Ph.D. Lecture Notes". Addis Ababa University, College of Veterinary Medicine, Debre Zeit, Ethiopia (2014): 1-41.

19. Al-Dughaym AM., et al. "First report of an outbreak of ovine septicaemic listeriosis in Saudi Arabia". Revue scientifique et technique - Office international des epizooties 20 (2001): 777783.

\section{Assets from publication with us}

- Prompt Acknowledgement after receiving the article

- Thorough Double blinded peer review

- Rapid Publication

- Issue of Publication Certificate

- High visibility of your Published work

Website: https://www.actascientific.com/

Submit Article: https://www.actascientific.com/submission.php

Email us: editor@actascientific.com

Contact us: +919182824667 